\title{
BMJ Open Spatial and demographic disparities in short stature among school children aged 7-18 years: a nation-wide survey in China, 2014
}

\author{
Jia Ma, ${ }^{\oplus, 2}$ Tao Pei, ${ }^{3}$ Fen Dong, ${ }^{4}$ Yanhui Dong, ${ }^{5}$ Zhaogeng Yang, ${ }^{5}$ Jie Chen, ${ }^{3}$ \\ Sihui Guo, ${ }^{3}$ Qiuling Zhao, ${ }^{6}$ Shunan Wang, ${ }^{1,2}$ Jun Ma, ${ }^{5}$ Zhixin Zhang ${ }^{2}$
}

To cite: Ma J, Pei T, Dong $\mathrm{F}$, et al. Spatial and demographic disparities in short stature among school children aged $7-18$ years: a nation-wide survey in China, 2014. BMJ Open 2019;9:e026634. doi:10.1136/ bmjopen-2018-026634

- Prepublication history and additional material for this paper are available online. To view these files, please visit the journal online (http://dx.doi. org/10.1136/bmjopen-2018026634).

JM and TP contributed equally.

Received 18 September 2018 Revised 14 May 2019 Accepted 10 June 2019

Check for updates

(C) Author(s) (or their employer(s)) 2019. Re-use permitted under CC BY-NC. No commercial re-use. See rights and permissions. Published by BMJ.

For numbered affiliations see end of article.

Correspondence to

Professor Jun Ma;

majunt@bjmu.edu.cn and

Professor Zhixin Zhang;

zhangzhixin032@163.com

\section{ABSTRACT}

Objectives To identify spatial disparities and demographic characteristics of short stature, we analysed the prevalence of short stature collected in a nationwide health survey.

Settings Data were obtained from the 2014 Chinese National Survey on Students Constitution and Health (a cross-sectional study of China). Participants came from 30 provinces, autonomous regions, and municipalities (except Tibet, Hong Kong, Macao, and Taiwan). Participants There were 213795 Han school children between 7 and 18 years old enrolled in our study. All participants were sampled by stratified cluster.

Primary and secondary outcome measures Short stature; Chinese and WHO age-specific and genderspecific height growth references were used for short stature assessment.

Results The age-standardised and age-genderstandardised prevalence of short stature nationwide was $3.70 \%$ and $2.69 \%$ according to Chinese and WHO growth references, respectively. The short stature prevalence differed significantly among age groups, urban and rural areas, and regions with different socioeconomic development levels (all $p<0.0001$ ). The prevalence was $2.23 \%$ in urban versus $5.12 \%$ in rural areas $(p<0.001)$. The prevalence was $2.60 \%$ in developed, $3.72 \%$ in intermediately developed, and $4.69 \%$ in underdeveloped regions $(p<0.0001)$. These values were all according to China's growth reference, but similar patterns were observed on prevalence based on the WHO reference. The spatial distribution of prevalence of short stature presented a clustered pattern. Moran's I value was $0.474(p<0.001)$ and 0.478 $(p<0.001)$ according to the Chinese and WHO growth references, respectively. The southwest part of China showed a higher prevalence of short stature, whereas lower prevalence of short stature was observed mainly in the northeast part of China.

Conclusions There is an appreciably high prevalence of short stature in rural, underdeveloped areas of China. There are high prevalence spatial clusters of short stature in southwestern China. This provides corroborating evidence for a tailored strategy on short stature prevention and reduction in special areas.
Strengths and limitations of this study

This is the first study to detect the spatial discrepancy of prevalence of short stature in mainland China.

- The results provide corroborating evidence for a tailored strategy on short stature prevention and reduction in special areas.

- Our study raises a discussion that because of the geographical and climatic differences between north and south China, we may need to consider regional differences in height when we diagnose short stature.

- Our study is a cross-sectional study. We did not explore the cause of short stature and did not perform a follow-up to learn the adult heights of our participants.

\section{INTRODUCTION}

Short stature is a major morbid condition for children who are referred to paediatric endocrinologists. ${ }^{1-3}$ About half of new visits to the paediatric endocrine department are harassed by short stature. ${ }^{4}$ It is usually caused by multiple factors, including children's nutritional status, repeated infections due to unsanitary environmental conditions, and the existence of several unknown endocrine metabolic disorders. ${ }^{5}$ The causes of short stature are a wide spectrum and mainly divided into normal (eg, familial short stature and constitutional delay of growth) and pathological (eg, growth hormone deficiency, Turner syndrome, hypothyroidism, chronic diseases, idiopathic short stature). ${ }^{6}$ It is regrettable that some of the causes of morbid status remained unidentified, and this is what we call idiopathic short stature. With the advancement of molecular diagnostic techniques, some unexplained causes for short stature have been gradually revealed. It can somewhat be attributed to genetic variation, indicating short stature as a phenotype of 
genetic diseases. ${ }^{4}$ Additionally, short stature affects children's physical and mental health. Children with short stature tend to suffer psychological disorders, such as low self-esteem, academic difficulties, social immaturity. ${ }^{7}$ Short stature can still affect children's health after they grow up. For instance, women with short stature were susceptible to have preterm birth when they became pregnant in adulthood. ${ }^{8}$ Therefore, identifying short stature in childhood is extremely important for physical and mental illness reduction and should be an imperative part of children's health programmes.

The prevalence of short stature varies greatly among different regions due to diverse social development and natural environment. ${ }^{9-12}$ It has been reported that children living in undeveloped areas were more likely to have stunted growth (or short stature). In 2017, the data showed that the prevalence of stunting in children under 5 years old in East and South Africa and South Asia was $34.1 \%$ and $35 \%$, respectively. ${ }^{13}$ Another study showed that children in north China were taller, on average, than children in south China. ${ }^{14}$ In addition, children living in economically developed areas such as Hong Kong (located in the south of China) were also susceptible to a certain percentage of short stature, indicating that there are other reasons that cause short stature ${ }^{15}$ For example, geographical and climate factors may play an important role in short stature. Is there a special spatial distribution of short stature in mainland China? Is this distribution associated with socioeconomic or geographical characteristics? Unfortunately, data related to the geographical distribution of short stature in China is seldom reported. To fill such a gap, we analysed the schoolchildren's height in a nationwide health survey, aiming to identify the spatial disparities and demographic characteristics of short stature.

\section{METHODS}

\section{Date collection and sampling}

Data were collected from the 2014 Chinese National Survey on Students Constitution and Health (CNSSCH), a national health survey on schoolchildren. Eligible participants were Han Chinese individuals aged 7-18 years old. The sampling procedures of CNSSCH have been reported. ${ }^{16}$ In summary, all participants were collected by stratified cluster sampling according to the principle of CNSSCH. Selected places in each province were graded into developed, intermediately developed, underdeveloped levels based on the local socioeconomic development. Subsequently, children were divided into four strata: urban boys, rural boys, urban girls, and rural girls. Then, 50 people were collected in each unit (for each year of age, gender, the urban/rural, developed/ intermediately developed/underdeveloped groups, and province). In the end, 213795 Han schoolchildren were enrolled in our study, and they came from 30 provinces, autonomous regions, or municipalities (except Tibet, Hong Kong, Macao, and Taiwan). The 18-year-old schoolchildren of Beijing could not be divided into three classes based on the condition of socioeconomic development, so we excluded the data of this group.

This study was conducted in accordance with the guidelines laid down in the Declaration of Helsinki. We obtained informed consent from parents and schoolchildren.

\section{Anthropometric measurements}

Standing height $(\mathrm{cm})$ was measured by trained staff following a standardised procedure, which was in accordance with the anthropometry methods in the 2006 WHO Child Growth Reference. ${ }^{17}$ Height was measured to the nearest $0.1 \mathrm{~cm}$ with portable stadiometers. Children stood without shoes, their heels were together with toes apart at a $60^{\circ}$ angle, and their backs were against a calibrated backboard.

Short stature is defined as a height below the third centile compared with children in the same age, gender, and ethnic population. ${ }^{18}$ In this study, we used China's and WHO's age-specific and gender-specific height growth references for short stature assessment. ${ }^{19}$

\section{Statistical analysis}

The demographic disparities of short stature were presented as a number (percent). Prevalence was age-standardised (or age-gender-standardised) directly to the China 2000 Census. Direct standardisation was conducted among provinces, municipalities, and autonomous regions to make comparisons of short stature across regions easier to interpret. The chi-square test was conducted to assess differences in prevalence of short stature among genders, age groups, urban/rural areas, and regions of different developmental levels. The Cochran-Armitage test was used for testing trend. Moran's I, Getis-Ord Gi*, and Anselin Local Moran's I were performed to identify spatial disparities. Getis-Ord $\mathrm{Gi}^{*}$ and Anselin Local Moran's I results were displayed on maps. Moran's I was proposed by Patrick Alfred Pierce Moran in 1950 to measure spatial autocorrelation. ${ }^{20} 21$ Moran's I ranges from -1 to $1 .{ }^{22}$ Values approach to zero means lacking a spatial association (ie, a random distribution), values approach to negative one means spatial dispersion, and values approach to positive one means clustering. ${ }^{22}$ Moran's I statistics with p-values less than 0.05 are considered statistically significant. Getis-Ord Gi* was proposed by Arthur Getis and Keith Ord in 1992. ${ }^{23}$ In our study, positive $\mathrm{Gi} * \mathrm{Z}$-scores indicate clustering of high prevalence of short stature, scores near 0 indicate no clustering existed, and negative scores suggest clustering of low prevalence of short stature. Local Moran's I, proposed by Luc Anselin in 1995, estimates intercluster variation. ${ }^{24}$ We used the Anselin Local Moran's I to estimate the spatial clustering of high-high clustering, low-low clustering, low-high clustering, and high-low clustering. ${ }^{22}$ Statistical analyses were performed using SAS V.9.4 (SAS Institute) and geographical disparities were analysed by ArcMap software V.10.2 (ESRI, Redlands, 
Table 1 Characteristics of participating children in the national survey in 2014

\begin{tabular}{llll}
\hline & N (\%) & & \\
\cline { 2 - 4 } Variables & $\begin{array}{l}\text { Boys } \\
\text { (n=106857) }\end{array}$ & $\begin{array}{l}\text { Girls } \\
\text { (n=106938) }\end{array}$ & $\begin{array}{l}\text { Both } \\
(\mathbf{n = 2 1 3 7 9 5 )}\end{array}$ \\
\hline Age (years) & $8944(8.37)$ & $8942(8.36)$ & $17886(8.37)$ \\
\hline 7 & $8903(8.33)$ & $8929(8.35)$ & $17832(8.34)$ \\
8 & $8962(8.39)$ & $8980(8.40)$ & $17942(8.39)$ \\
\hline 9 & $8972(8.40)$ & $8967(8.39)$ & $17939(8.39)$ \\
\hline 10 & $8982(8.41)$ & $8937(8.36)$ & $17919(8.38)$ \\
11 & $8953(8.38)$ & $8951(8.37)$ & $17904(8.37)$ \\
12 & $8968(8.39)$ & $8982(8.40)$ & $17950(8.40)$ \\
\hline 13 & $8964(8.39)$ & $8969(8.39)$ & $17933(8.39)$ \\
\hline 14 & $8973(8.40)$ & $8987(8.40)$ & $17960(8.40)$ \\
\hline 15 & $8960(8.39)$ & $8967(8.39)$ & $17927(8.39)$ \\
\hline 16 & $8952(8.38)$ & $8980(8.40)$ & $1632(8.39)$ \\
\hline 17 & $8324(7.79)$ & $8347(7.81)$ & $107039(50.07)$ \\
\hline 18 & & & $106756(49.93)$ \\
\hline Residence & $53502(50.07)$ & $53537(50.06)$ & $71271(33.34)$ \\
\hline Urban & $53355(49.93)$ & $53401(49.94)$ & $71279(33.34)$ \\
\hline Rural & & & $71245(33.32)$ \\
\hline Socioeconomic development & $35567(33.28)$ & $35704(33.39)$ & \\
\hline Developed & $35659(33.37)$ & $35620(33.31)$ & \\
\hline Intermediately developed & $35631(33.34)$ & $35614(33.30)$ & \\
\hline Under-developed & & & \\
\hline
\end{tabular}

California, USA). P values less than 0.05 (two-sided) were considered statistically significant.

\section{Patient and public involvement}

Participants were not involved in the design of this study.

\section{RESULTS}

\section{Characteristics of participating children}

In total, 213795 children, comprising 106857 boys and 106938 girls, were enroled in our study. The participants were distributed evenly between sexes (ie, the ratio of boys and girls was close to 1:1) and among the groups of different ages, urban-rural areas, and regions with different socioeconomic development levels (table 1).

\section{Prevalence of short stature}

The nationwide prevalence of short stature was $3.67 \%$ and $2.70 \%$ according to the Chinese and WHO growth references, respectively. Based on the Chinese growth reference, short stature prevalence differed significantly among age groups, urban-rural areas, and regions with different socioeconomic development levels (all $\mathrm{p}<0.0001)$. This was especially true for urban versus rural areas (ie, 2.23 vs $5.12 \%$, respectively; $\mathrm{p}<0.0001$ ) and regions of varying socioeconomic development (ie, 2.60 in developed, $3.72 \%$ in intermediately developed, and $4.69 \%$ in underdeveloped regions; $\mathrm{p}<0.0001$ ) (table 2 and figure 1A). Similar patterns were observed in the short stature prevalence based on the WHO reference (table 2 and figure 1A). The age-standardised and agegender-standardised prevalence of short stature nationwide was $3.70 \%$ and $2.69 \%$ according to the Chinese and WHO growth references, respectively. Notedly, the prevalence of short stature defined by the Chinese reference was higher than that based on the WHO reference.

We did not observe a gender difference in overall prevalence of short stature according to the Chinese growth reference $(p=0.260)$. However, we observed this difference in prevalence evaluated by the WHO growth reference $(p<0.0001)$. Since we found significant differences of prevalence of short stature in urban and rural areas and regions with different socioeconomic development levels, we then explored further to see if a gender difference of short stature existed in different areas and regions. Based on the Chinese reference, results (table 3) showed that there are no significant differences in prevalence of short stature between genders in urban or rural areas or in regions of different socioeconomic development levels. According to the WHO reference, there are significant differences in gender between urban or rural areas and among all the regions of different socioeconomic development levels.

Then, we drew trajectories of prevalence of short stature across different ages for boys and girls in different areas of residence (urban/rural) and regions (ie, developed, intermediately developed, or underdeveloped) 
Table 2 Prevalence of short stature in boys and girls according to China and WHO references

Prevalence, \%

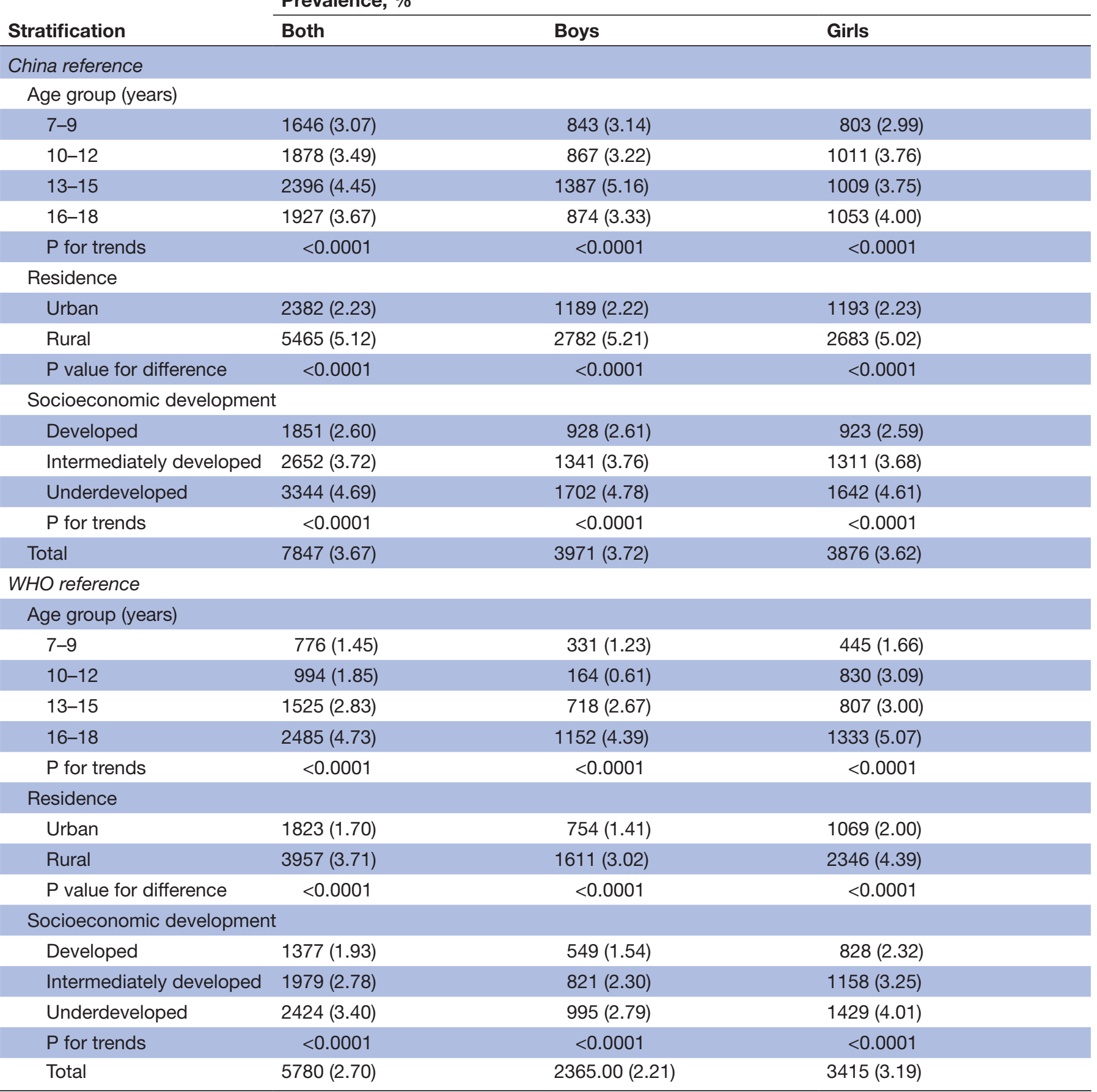

(figure 1B,C, and online supplementary figure 1). The high prevalence of short stature in rural or undeveloped regions are consistent across all ages. In addition, we had two interesting findings that applied to all children no matter whether they lived in urban or rural areas or regions of different socioeconomic development levels. The first is that, in most cases, although the trajectories of short stature prevalence in different age groups fluctuated, the lowest point was always in the 10-12 age group for boys and in the 7-9 age group for girls. The second finding is that, in most cases, the peak of prevalence of short stature appeared after the lowest point. Some of them followed closely in the next age group while others appeared in the 16-18 age group.

\section{Spatial characteristics of short stature}

The spatial distribution of prevalence of short stature presented a clustered pattern. Moran's I value was 0.474 $(\mathrm{p}<0.001)$ and $0.478(\mathrm{p}<0.001)$ according to the Chinese and WHO growth references, respectively. The maps of prevalence of short stature (figure 2A,B and online supplementary table 1) indicated that the distribution of prevalence 

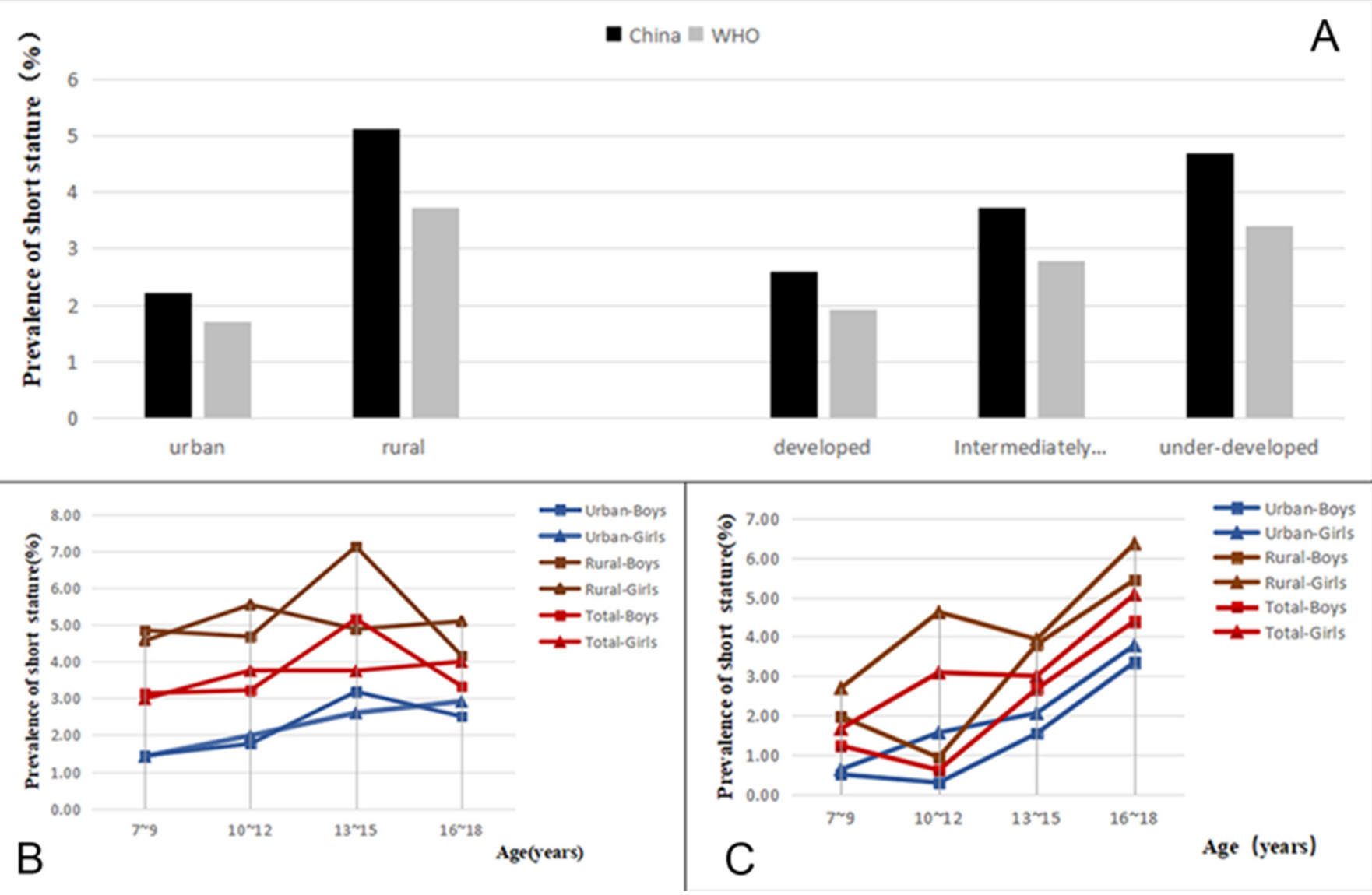

Figure 1 (A) The discrepancy of prevalence between urban-rural and different regions. (B) The discrepancy of prevalence between different age groups according China growth reference. $(C)$ The discrepancy of prevalence between different age groups according to WHO growth reference.

was spatially different. Southwest China showed higher prevalence of short stature while northeast China had comparatively lower prevalence. Anselin Local Moran I indicated that there was a high-high cluster in Sichuan, Guizhou, Guangxi, Guangdong, Chongqing, Hainan, Hunan, and Yunnan. A low-low cluster existed in some other provinces like Liaoning, Jilin, Inner Mongolia, Beijing, Tianjin, Hebei, Shanxi, Shandong, Jiangsu, Shanghai, Zhejiang, and Anhui (figure 2C,D and online supplementary table 2).

Table 3 Discrepancy of genders in different residence and regions

\begin{tabular}{|c|c|c|c|c|}
\hline \multirow[b]{2}{*}{ Stratification } & \multicolumn{2}{|c|}{ China reference } & \multicolumn{2}{|c|}{ WHO reference } \\
\hline & $\chi^{2}$ & $P$ value & $\chi^{2}$ & $P$ value \\
\hline \multicolumn{5}{|l|}{ Residence } \\
\hline Urban & 0.004 & 0.947 & 55.163 & $<0.0001$ \\
\hline Rural & 1.981 & 0.159 & 141.122 & $<0.0001$ \\
\hline \multicolumn{5}{|c|}{ Socioeconomic development } \\
\hline Developed & 0.041 & 0.840 & 56.555 & $<0.0001$ \\
\hline $\begin{array}{l}\text { Intermediately } \\
\text { developed }\end{array}$ & 0.319 & 0.572 & 59.406 & $<0.0001$ \\
\hline Underdeveloped & 1.100 & 0.294 & 80.656 & $<0.0001$ \\
\hline Total & 1.270 & 0.260 & 195.227 & $<0.0001$ \\
\hline
\end{tabular}

These results were consistent between the two references. According to the Chinese growth reference, Getis-Ord Gi* identified the following as hotspot-99\% confidence areas: Sichuan, Yunnan, Guizhou, Guangxi, and Hainan. The hotspot-95\% confidence areas were Chongqing, Hunan, and Guangdong. The hotspot-90\% confidence area was Gansu. The coldspot-99\% confidence areas were Liaoning, Beijing, Tianjin, Hebei, Shandong, Shanghai, and Jiangsu. The coldspot-95\% confidence areas were Zhejiang, Anhui, Jilin, Inner Mongolia, and Shanxi (figure 2E and online supplementary table 3). According to the WHO growth reference, Getis-Ord Gi* identified the following hotspot99\% confidence areas: Sichuan, Yunnan, Guizhou, Guangxi, and Hainan. The hotspot-95\% confidence areas were Chongqing, Hunan, and Guangdong. The coldspot-99\% confidence areas were Liaoning, Beijing, Tianjin, Hebei, Shandong, Shanghai, and Jiangsu. The coldspot-95\% confidence areas were Anhui, Jilin, Inner Mongolia, and Shanxi. The coldspot-90\% confidence area was Zhejiang (figure 2F online supplementary table 3 ).

\section{DISCUSSION}

In our study, the age-standardised and age-gender-standardised prevalence of short stature nationwide was $3.70 \%$ and $2.69 \%$ according to Chinese and WHO 


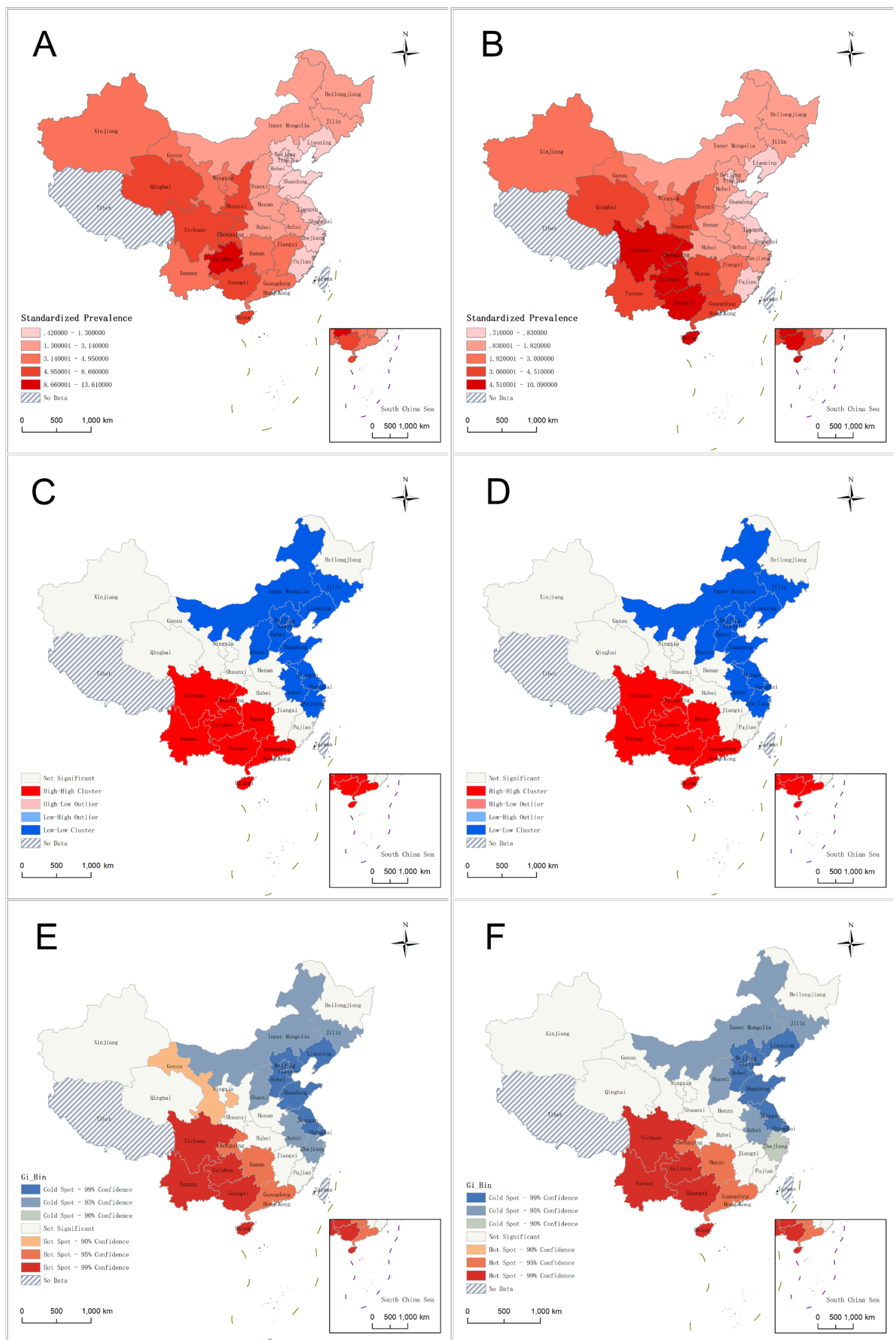

Figure 2 (A) The distribution of standardised prevalence according to China growth reference. (B) The distribution of standardised prevalence according to WHO growth reference. (C) The results of Anselin Local Moran's I about standardised prevalence according to China growth reference. (D) The results of Anselin Local Moran's I about standardised prevalence according to WHO growth reference. (E) The result of Hotspot Getis-Ord, Gi* about standardised prevalence according to China growth reference. (F) The result of Hotspot Getis-Ord, $\mathrm{Gi}^{\star}$ about standardised prevalence according to WHO growth reference. 
growth references, respectively. Regarding the terminology of short stature, it is sometimes synonymous to 'stunted growth' and also known as stunting or nutritional stunting in children. According to WHO, stunting is defined as a Height-for-age Z-score <-2SD (SD) of the WHO Child Growth References. ${ }^{25}$ In China, the definition of short stature is a height-for-age below the third centile $(-1.88 \mathrm{SD})$ or less than $2 \mathrm{SD}$ compared with average height of children of the same age and gender. ${ }^{18}$ Globally, the prevalence of stunting under 5 years old declined from $32.6 \%$ to $22.2 \%$ between 2000 and $2017 .{ }^{13}$ One study in 2014 showed that the crude prevalence of stunting in Chinese schoolchildren between 7 and 18 years old was $2.3 \%$ based on the WHO growth reference, which is lower than our result. This difference could be partly attributed to the different SD adopted in our study. We used the third centile $(-1.88 \mathrm{SD})$ to define short stature, which is currently routine clinical practice in China. In Song's study, -2 SD was used to assess stunting, which may have contributed to less diagnoses and a lower prevalence compared with our study. Their study also showed that, from 1985 to 2014, the national crude prevalence of stunting in Chinese schoolchildren decreased from $16.4 \%$ to $2.3 \% .{ }^{26}$ Another study in Hong Kong processed in 2005 showed that the crude prevalence of short stature (ie, height below the third centile) was $1.7 \%$ in $6-10$-year-old children and was $4.4 \%$ in children aged 11-18 years based on the WHO growth reference. World Bank data showed that the prevalence of stunting in 2015 among children under 5 years old in South Asia, Sub-Saharan Africa, the Middle East and North Africa, East Asia and the Pacific, Latin America and the Caribbean, and Europe and Central Asia was 36.2, 35.2, 15.8, $14.4,10.1$, and $9.2 \%$, respectively. ${ }^{27}$ In conclusion, the total prevalence of short stature among Chinese schoolchildren being low and having a decreased trend may reflect improvements in many aspects of China in recent years. The prevalence of short stature helps us to know the nutritional and pathological condition of children and provide useful data to decision makers.

The prevalence of short stature was considerably higher in rural areas than in urban ones. The prevalence in the former was nearly 2.5 times higher than in the latter. With respect to regions with different socioeconomic development levels, we observed a climbing trend of short stature in under- and intermediately developed regions compared with developed ones. Both the higher prevalence in rural areas and less developed regions indicated that children living in socioeconomically delayed areas were at higher risk of having stunted growth. Based on the WHO growth reference, the prevalence of stunting in children was $16.4 \%$ and $5.7 \%$ in rural and urban China, respectively, in 2002. ${ }^{28}$ Economic development of China does not reduce inequalities in nutrition and healthcare services. ${ }^{29}$ A study has shown that there have been declining trends of urban-rural disparities since China's Reform and Opening Policy was established in 1978. ${ }^{30}$ However, the difference in the prevalence of short stature in rural and urban areas is still a concern. This inequality reminds us the need for policies to be implemented in this area.

Our study has shown differences in prevalence between age groups. These differences may be mainly because the increase of height in human beings does not occur at a constant velocity. The highest growth rate occurs in fetal life and infancy, then slows down during childhood, and the acceleration happens during puberty. ${ }^{31}$ The acceleration of the rate of height growth in puberty can partly explain the differences in prevalence of short stature in different age groups. When does puberty begin in Chinese adolescents? Girls may begin puberty earlier than boys. ${ }^{32} 33$ One study showed that the median age of menarche in Chinese girls was 12.47 years in $2010 .{ }^{34}$ Puberty starts almost 2 years before the age of menarche in girls. The median age of puberty onset (ie, testicular volume is $4 \mathrm{~mL}$ or greater) in urban Chinese boys was 10.55 years between 2003 and $2005 .^{35}$ Another study showed that the menarche of Hong Kong Chinese girls occurred at 12.1 years, and the first nocturnal ejaculation occurred at 13.0 years for Hong Kong Chinese boys in $1996 .{ }^{36}$ The timing of puberty reported by literature is consistent with our study results. The lowest point of prevalence of short stature occurred in the 10-12 age groups for boys and 7-9 age groups for girls, respectively. At these ages, Chinese boys and girls start puberty. The rate of height growth accelerated, and the prevalence of short stature lowered correspondingly. The phenomena of the peak appearing after the lowest point may indicate that, after puberty, the growth rate gradually decreased in these age groups, especially in the 16-18 age group. One study showed that most Chinese children will stop growing height by the time they reach 18 years of age. ${ }^{19}$ On account of these changes in growing height rate during puberty, the diagnosis of short stature may be prudent for children between 7 and 18 years old.

As for gender differences in prevalence of short stature, the two growth references gave opposite results. We found that, in the 10-12 age group, the prevalence of short stature in boys based on the WHO reference was low at $0.61 \%$ (figure 2 ). We think that the reason behind this is related to the acceleration of puberty in Chinese boys of this age group and to the fact that the data of the WHO reference did not detect boys who are really short stature. Two studies in Argentinian and Polish children showed growth variations, especially in adolescents, when comparing the WHO growth reference data with the recommend national references for clinical use. ${ }^{37} 38$ Another study showed that Asian subpopulations have an earlier onset of puberty than other ethnic groups. ${ }^{39}$ In conclusion, using US children pubertal growth patterns (ie, WHO reference for 5-19 years based on the data of the US population) to assess Chinese children pubertal growth patterns may be inappropriate. We recommend the use of the Chinese growth reference for clinical assessment of Chinese adolescent. 
In terms of spatial distribution, our study showed that the prevalence of short stature was higher in southwest of China but lower in northeast China. With the development of the geographic information system (GIS) technique, the research on the spatial distribution for diseases has gradually attracted people's attention. ${ }^{22} 40-43$ A study from Somalia shows that there is a high prevalence of stunting in the south area of the country, especially around the two main rivers of Juba and Shebelle. ${ }^{11}$ There is a study in Ethiopia showing that they identified clusters of high prevalence of stunting in the eastern part and clusters of low prevalence in the western part of the district. ${ }^{12}$ In our study, we tried to explore the spatial discrepancy of prevalence of short stature in mainland China using Moran's I, Getis-Ord Gi*, and Anselin Local Moran's I, which are widely used in exploring the spacetime pattern of diseases. Our research shows that there is a significant difference in the prevalence of short stature in different areas of China. Specifically, there is a higher prevalence cluster for short stature in the southwestern region, especially in the Sichuan, Guizhou, Guangxi, Guangdong, Chongqing, Hainan, and Yunnan provinces. In the northeast region, there was a lower prevalence cluster for short stature, especially in Inner Mongolia, Beijing, Tianjin, Hebei, Liaoning, Jilin, Shandong, Shanxi, Shanghai, Zhejiang, Anhui, and Jiangsu. What accounts for this spatial discrepancy? Socioeconomic factors may account for something. ${ }^{45}$ Two studies about spatial difference of stunting mentioned above found that maternal education, food security, and access were associated with stunting. ${ }^{112}$ In addition, the discrepancies in some disease conditions, such as repeated infections and endocrine metabolic disease, may affect the distribution of short stature. It is a complicated situation, and we hope we can deeply research this in future studies.

Another study that caught our attention found that, in mainland China, children of 7-18 years old living in the north had a higher height than children in the south on average. ${ }^{14}$ The maximum height difference of different regions was almost 4 to $5 \mathrm{~cm} .{ }^{14}$ China is not a country of immigrants. Residents have lived here for thousands of years, and residents and the natural environment have developed adaptations. Because there is a disparity in the geographical and climatic environment between south and north China, we believe that the geographical and climatic factor may play an important role in short stature. First, altitudes may be an important factor for height growth and is associated with short stature. Peruvians and Tibetans lived at high altitude places and tend to be short. ${ }^{46-48}$ Because of the high altitude environment, the body's functions will exhibit high-altitude adaptations, such as larger lungs, better lung function, lower blood haemoglobin concentration, that may not be found in lowlanders. ${ }^{49}$ Short stature may be another type of adaption because animals living in high elevations tend to be smaller to adapt to an environment with a scarcity of food. ${ }^{46}$ Even European settlers living in the Andes had statures $1-5 \mathrm{~cm}$ shorter than their compatriots living in lowland areas. ${ }^{50}$ Moreover, temperature, rainfall, and extreme weather events (floods/droughts) were reported to be associated with short stature ${ }^{51-53}$ Regrettably, we did not explore the causes of short stature. The geographical and climatic factor may determine short stature to some degree. Therefore, children who live in hotspot areas (some places in southwestern China) will be diagnosed with short stature though they do not have a pathological condition. The prevalence of short stature will be overestimated. The solutions for this are to build growth reference based on the same area population or lower the cut-off value to diagnose short stature in these places. ${ }^{48}$ We must be more prudent when we diagnose short stature of children from these areas and avoid excessive laboratory tests or therapy for these children. Further studies on this subject are needed, and we hope our study is raising a discussion on the topic.

\section{Limitations}

Height varies between different population groups worldwide. ${ }^{55}$ The Dutch population is the tallest and the Peruvian population is the shortest population in the word. ${ }^{46} 56$ Even immigrants will retain genetic potential for height, as observed in Turkish children. ${ }^{57}$ The definition of short stature emphasises that the comparison of height needs to be taken between the same population group, race, or ethnicity. ${ }^{58}$ There are 56 ethics groups (nationalities) in China, as shown by the 2011 National Population Census data. Of the Chinese population, $91.51 \%$ are of Han nationality and $8.49 \%$ are of 'minority nationalities. ${ }^{59}$ A study compared the height of minority nationalities with Han schoolchildren in southwest China. Results showed that the age of the rapid growth period in the southwest China minority nationality group was greater than that in the Han schoolchildren. ${ }^{60}$ Another study showed that the stunting prevalence of Tibetan children in Lasa (Tibet) was higher than the national prevalence. ${ }^{61}$ Based on the above, the adult height or growth pattern of some minority nationalities may differ from the Han nationality in China, and it may be insightful to know the condition of short stature in these ethnic minorities to see if it is different to other groups (ie, the Han nationality or other nationalities) who live in same geographical environment. Although we did not evaluate the short stature of ethnic minorities in our study, it is a meaningful research direction for later scholars. In our study, we also did not exclude the effect of the floating population (ie, individuals whose growth place and birth place are not the same). Because our study is cross-sectional, we also did not explore the causes of short stature and we did not perform a follow-up to learn the adult heights of our participants.

\section{CONCLUSIONS}

There is an appreciably high prevalence of short stature in rural, underdeveloped areas of China. This provides corroborating evidence for a tailored strategy for short 
stature prevention and reduction in special areas. We also uncover that there are high prevalence spatial clusters of short stature in the southwestern China, such as Sichuan, Guizhou, Guangxi, Guangdong, Chongqing, Hainan, Yunnan provinces. Therefore, further study needs to be done in these places to detect the cause of short stature. Our results indicate that, aside from the racial factor, the regional factor may need to be considered when defining short stature.

\section{Author affiliations}

${ }^{1}$ Graduate School, Beijing University of Chinese Medicine, Beijing, China ${ }^{2}$ Department of Pediatrics, China-Japan Friendship Hospital, Beijing, China ${ }^{3}$ State Key Laboratory of Resources and Environmental Information System, Institute of Geographical Sciences and Natural Resources Research, Chinese Academy of Sciences, Beijing, China

${ }^{4}$ Institute of Clinical Medical Sciences, China-Japan Friendship Hospital, Beijing, China

${ }^{5}$ Institute of Child and Adolescent Health \& School of Public Health, Peking University, Beijing, China

${ }^{6}$ Department of Pediatrics, Beijing Chaoyang District Maternal and Child Health Care Hospital, Beijing, China

Acknowledgements We want to acknowledge the participants and health staffs in the survey. We want to acknowledge selfless assistance of Wenquan Niu PhD (Institute of Clinical Medical Sciences, China-Japan Friendship Hospital). At the same time, we want to acknowledge editors and reviewers' work devoted to our manuscript and we are very grateful for their valuable suggestions.

Contributors ZZ and JunM worked together to develop the research question, study design and analytic plan. YD and ZY collected and collated data of short stature prevalence in different genders, regions, ages groups from CNSSCH data. $\mathrm{JM}$ wrote the manuscript. FD analyzed demographic characteristics of data by mathematical statistics and revised the manuscript. TP, JC, SG analysed spatial distribution of short stature and TP helped to revised the manuscript. QZ and SW helped to apply the research fund and check the data. All authors have contributed to the work and approved the manuscript.

Funding This study was funded by National Natural Science Foundation of China (grant number: 41571376 and 41525004).

Map disclaimer The depiction of boundaries on the map(s) in this article do not imply the expression of any opinion whatsoever on the part of BMJ (or any member of its group) concerning the legal status of any country, territory, jurisdiction or area or of its authorities. The map(s) are provided without any warranty of any kind, either express or implied.

Competing interests None declared.

Patient consent for publication Not required.

Ethics approval The project was approved by the Medical Research Ethics Committee of Peking University Health Science Center (IRB00001052-13082), Clinical Research Ethics Committee of China-Japan Friendship Hospital (2018-94-K68).

Provenance and peer review Not commissioned; externally peer reviewed.

Data sharing statement No additional data are available.

Open access This is an open access article distributed in accordance with the Creative Commons Attribution Non Commercial (CC BY-NC 4.0) license, which permits others to distribute, remix, adapt, build upon this work non-commercially, and license their derivative works on different terms, provided the original work is properly cited, appropriate credit is given, any changes made indicated, and the use is non-commercial. See: http://creativecommons.org/licenses/by-nc/4.0/.

\section{REFERENCES}

1. Smuel K, Yeshayahu Y. "Real-world" pediatric endocrine practice; how much is it influenced by physician's gender and region of practice. Results of an international survey. J Eval Clin Pract 2017;23:866-9.
2. Tornese G, Pellegrin MC, Barbi E, et al. Pediatric endocrinology through syndromes. Eur J Med Genet 2019.

3. Rogol AD, Hayden GF. Etiologies and early diagnosis of short stature and growth failure in children and adolescents. J Pediatr 2014;164(5 Suppl):S1-14.

4. Murray PG, Clayton PE, Chernausek SD. A genetic approach to evaluation of short stature of undetermined cause. Lancet Diabetes Endocrinol 2018;6:564-74.

5. Stewart CP, lannotti L, Dewey KG, et al. Contextualising complementary feeding in a broader framework for stunting prevention. Matern Child Nutr 2013;9(Suppl 2):27-45.

6. Allen DB, Cuttler L. Clinical practice. Short stature in childhood-challenges and choices. N Engl J Med 2013;368:1220-8.

7. Kim B, Park MJ. The influence of weight and height status on psychological problems of elementary schoolchildren through child behavior checklist analysis. Yonsei Med J 2009;50:340-4.

8. Derraik JG, Lundgren M, Cutfield WS, et al. Maternal Height and Preterm Birth: A Study on 192,432 Swedish Women. PLoS One 2016;11:e0154304.

9. Black RE, Victora CG, Walker SP, et al. Maternal and child undernutrition and overweight in low-income and middle-income countries. Lancet 2013;382:427-51.

10. Marshall WA. Geographical and ethnic variations in human growth. Br Med Bull 1981;37:273-9.

11. Kinyoki DK, Kandala NB, Manda SO, et al. Assessing comorbidity and correlates of wasting and stunting among children in Somalia using cross-sectional household surveys: 2007 to 2010. BMJ Open 2016;6:e009854.

12. Hagos S, Hailemariam D, WoldeHanna T, et al. Spatial heterogeneity and risk factors for stunting among children under age five in Ethiopia: A Bayesian geo-statistical model. PLoS One 2017; 12:e0170785.

13. United Nations International Children's Emergency Fund. Malnutrition prevalences remain alarming: stunting is declining too slowly while wasting still impacts the lives of far too many young children. 2018 https://data.unicef.org/topic/nutrition/malnutrition/

14. Cai $\mathrm{CH}$, Dong B, Ma J. [District differences and regional division of heights among Chinese Han children and adolescents]. Zhonghua Liu Xing Bing Xue Za Zhi 2012;33:197-200.

15. So HK, Nelson EA, Sung RY, et al. Implications of using World Health Organization growth reference (2007) for identifying growth problems in Hong Kong children aged 6 to 18 years. Hong Kong Med $J$ 2011;17:174-9.

16. Research Group of the Physical Fitness and Health Surveillance of Chinese school students. Report on the Physical Fitness and Health Surveillance of Chinese School Students. Beijing, China.: High Education Press, 2016.

17. de Onis M, Onyango AW. WHO child growth standards. Lancet 2008;371:204.

18. Chinese Society of Pediatric Endocrinology and Metabolism. Guideline for diagnosis and treatment of short stature children. Chinese Journal of Pediatrics 2008;46:20-1.

19. Li H, Ji CY, Zong XN, et al. [Height and weight standardized growth charts for Chinese children and adolescents aged 0 to 18 years]. Zhonghua Er Ke Za Zhi 2009;47:487-92.

20. MORAN PA. Notes on continuous stochastic phenomena. Biometrika 1950;37:17-23.

21. Bernstein RM, Dufour DL. Special Section: Worldwide variation in human growth: 40 years later. Am J Hum Biol 2017;29:e22984.

22. Brownwright TK, Dodson ZM, van Panhuis WG. Spatial clustering of measles vaccination coverage among children in sub-Saharan Africa. BMC Public Health 2017;17:957.

23. Getis A, Ord JK. The Analysis of Spatial Association by Use of Distance Statistics. Geogr Anal 2010;24:189-206.

24. Anselin L. Local Indicators of Spatial Association-LISA. Geogr Anal 1995;27:93-115.

25. World Health Organization. Child malnutrition. http://www.who.int/ gho/health_equity/outcomes/health_equity_child_malnutrition_a. pdf

26. Song $\mathrm{Y}$, Agardh $\mathrm{A}, \mathrm{Ma} \mathrm{J}$, et al. National trends in stunting, thinness and overweight among Chinese school-aged children, 1985-2014. Int J Obes 2019;43:402-11.

27. UNICEF WHO, World Bank Group. Joint Child Malnutrition Estimates - Levels and Trends. 2016 http://www.who.int/nutgrowthdb/ estimates2015/en/.

28. Li YP, Hu XQ. Application of the WHO growth reference (2007) to assess the nutritional status of children in China. Biomed Environ Sci 2009;22:130-5

29. Hsiao WC, Liu Y. Economic reform and health--lessons from China. N Engl J Med 1996;335:430-2. 
30. Liu H, Fang H, Zhao Z. Urban-rural disparities of child health and nutritional status in China from 1989 to 2006. Econ Hum Biol 2013;11:294-309.

31. Tanner JM, Davies PS. Clinical longitudinal standards for height and height velocity for North American children. J Pediatr 1985;107:317-29.

32. Karlberg J. On the construction of the infancy-childhood-puberty growth standard. Acta Paediatr Scand Suppl 1989;356:26-37.

33. Tanner JM, Whitehouse RH, Marubini E, et al. The adolescent growth spurt of boys and girls of the Harpenden growth study. Ann Hum Biol 1976;3:109-26.

34. Song Y, Ma J, Wang HJ, et al. Trends of age at menarche and association with body mass index in Chinese school-aged girls, 1985-2010. J Pediatr 2014;165:1172-7.

35. Ma HM, Chen SK, Chen RM, et al. Pubertal development timing in urban Chinese boys. Int J Androl 2011;34(5 Pt 2):e435-45.

36. Lam TH, Shi HJ, Ho LM, et al. Timing of pubertal maturation and heterosexual behavior among Hong Kong Chinese adolescents. Arch Sex Behav 2002;31:359-66.

37. Orden AB, Apezteguía MC. Weight and height centiles of Argentinian children and adolescents: a comparison with WHO and national growth references. Ann Hum Biol 2016;43:9-17.

38. Kulaga Z, Litwin M, Tkaczyk M, et al. The height-, weight-, and BMI-for-age of Polish school-aged children and adolescents relative to international and local growth references. BMC Public Health 2010;10:109.

39. de Wilde JA, van Dommelen P, van Buuren S, et al. Height of South Asian children in the Netherlands aged 0-20 years: secular trends and comparisons with current Asian Indian, Dutch and WHO references. Ann Hum Biol 2015;42:38-44.

40. Osgood-Zimmerman A, Millear Al, Stubbs RW, et al. Mapping child growth failure in Africa between 2000 and 2015. Nature 2018;555:41-

41. Mantri S, Fullard M, Gray SL, et al. Patterns of dementia treatment and frank prescribing errors in older adults with parkinson disease. JAMA Neurol 2019;76:41-9.

42. Kershaw KN, Robinson WR, Gordon-Larsen P, et al. Association of changes in neighborhood-level racial residential segregation with changes in blood pressure among black adults: the CARDIA Study. JAMA Intern Med 2017;177:996.

43. Xu X, Zhou G, Wang Y, et al. Microgeographic Heterogeneity of Border Malaria During Elimination Phase, Yunnan Province, China, 2011-2013. Emerg Infect Dis 2016;22:1363-70.

44. Wang A, Scherpbier RW, Huang X, et al. The dietary diversity and stunting prevalence in minority children under 3 years old: a crosssectional study in forty-two counties of Western China. Br J Nutr 2017;118:840-8.
45. Wu L, Yang Z, Yin SA, et al. The relationship between socioeconomic development and malnutrition in children younger than 5 years in China during the period 1990 to 2010. Asia Pac J Clin Nutr 2015;24:665-73.

46. Pennisi E. High altitude may have driven short stature in Peruvians. Science 2018;360:696.

47. Tripathy V, Gupta R. Growth among Tibetans at high and low altitudes in India. Am J Hum Biol 2007;19:789-800.

48. Weitz CA, Garruto RM. Stunting and the prediction of lung volumes among tibetan children and adolescents at high altitude. High Alt Med Biol 2015;16:306-17.

49. Wu T, Kayser B. High altitude adaptation in Tibetans. High Alt Med Biol 2006;7:193-208.

50. Greksa LP. Growth and development of Andean high altitude residents. High Alt Med Biol 2006;7:116-24.

51. Wells JC. Environmental temperature and human growth in early life. $J$ Theor Biol 2000;204:299-305.

52. Serrat MA. Environmental temperature impact on bone and cartilage growth. Compr Physiol 2014;4:621-55.

53. Phalkey RK, Aranda-Jan C, Marx S, et al. Systematic review of current efforts to quantify the impacts of climate change on undernutrition. Proc Natl Acad Sci U S A 2015;112:E4522-9.

54. Natale V, Rajagopalan A. Worldwide variation in human growth and the World Health Organization growth standards: a systematic review. BMJ Open 2014;4:e003735.

55. Haas JD, Campirano F. Interpopulation variation in height among children 7 to 18 years of age. Food Nutr Bull 2006;27:S212-23.

56. Schönbeck $Y$, Talma H, van Dommelen P, et al. The world's tallest nation has stopped growing taller: the height of Dutch children from 1955 to 2009. Pediatr Res 2013;73:371-7.

57. Arı Yuca S, Cesur Y, Kurtoğlu S, et al. Growth patterns of children of same geographic background reared in different environments. J Clin Res Pediatr Endocrinol 2014;6:233-7.

58. Ranke MB. Towards a consensus on the definition of idiopathic short stature. Horm Res 1996;45 Suppl 2(Suppl 2):64-6.

59. Wu X. From Assimilation to Autonomy: Realizing Ethnic Minority Rights in China's National Autonomous Regions. Chinese Journal of International Law 2014;13:55-90.

60. Ning Li XG. Comparative research on the variation characteristics of height and growth of minority nationalities students with Han nationality aged from 7 to 18 in southwest China. Modern Preventive Medicine 2009;36:445-9.

61. Yin XJ, Ji CY. Malnutrition prevalence in lasa xizang children and adolescents. Biomed Environ Sci 2014;27:614-26. 